\title{
O LATIM MEDIEVAL: UMA TENTATIVA DE CONCEITUAÇĀO
}

\author{
MARIA DO HORTO SOARES MOTTA \\ Doutor em Letras*
}

Não é tarefa fácil tentar conceituar o latim medieval. Para começar, convém lembrar que esse latim nem sempre mereceu a atenção dos estudiosos, que o julgavam, em muitos casos, uma língua mais ou menos artificial e desprovida de interesse.

Wilhelm MEYER e Ludwig TRAUBE (apud LEHMANN, 1911) foram dos primeiros a tomar consciência de sua importância e a chamar a atenção para o interesse e o significado de que se revestiam os estudos e as pesquisas em torno da língua e da literatura latina medieval, ressaltando a necessidade de um tratamento cientifico dos problemas aí envolvidos.

Não há unanimidade entre os autores quanto a classificar o latim da Idade Média como uma língua morta ou como uma língua viva, do que resulta uma grande variedade de conceituações.

TRAUBE (apud MOHRMANN, 1955) considera-o uma língua morta, mas nđơ invariável, à semelhança de um cadáver cujos cabelos e unhas, segundo a crença popular, continuam crescendo. Essa imagem usada por TRAUBE faz lembrar uma outra de Charles THUROT, que, em 1968, comparava o latim medieval a um animal selvagem que, aprisionado em uma jaula, estava impedido de desenvolver todos os seus dons, todas as suas faculdades, mas que era capaz de, vez por outra, manifestar sua força e beleza naturais.

Para Karl VOSSLER (apud MOHRMANN, 1955), ele é uma forma intermediária entre língua viva e língua morta. Tendo começado como língua morta, vai aos poucos se vivificando, no próprio contato com o mundo medieval.

P. LEHMANN (LEHMANN, 1911), discípulo de TRAUBE, segue uma linha de pensamento semelhante à de seu mestre ao ver o latim medieval como uma língua viva, mas sujeita á certas limitações.

Karl STRECKER inicia sua Introduction a l'étude du latin medieval afirmando:

"O latim da Idade Média deve ser estudado em sua evolução histórica. O latim clássico não cessou de existir certo dia para ser substituŕdo, nesse mesmo dia, por outro latim, o latim medieval. O latim da Idade Média é, pelo contrário, a continuação normal do latim clássico, na forma evoluída com que se apresenta nas obras dos escritores da baixa latinidade." (STRECKER, 1948, p. 15)

"Professor Adjunto do Departamento de Letras Clássicas e Vernáculas, Instituto de Letras da Universidade Federal do Rio Grande do Sul. 
LÖEFSTEDT (apud MOHRMANN, 1955), o grande estudioso de latim tardio declarava-se cada vez mais convencido da existência de uma continuidade entre 0 latim tardio e o medieval, havendo uma transição gradual entre um e outro, pelo que se pode atribuir à latinidade medieval uma vida normal e orgânica.

Em seu Manuel pratique de latin médiéval, Dag NORBERG, um dos maiores especialistas no assunto, assevera que "... esse latim não é uma língua nova e autônoma, mas a continuação culta e escolar do làtim na época romana." (NORIIERG, 1968, p. 14). No capítulo I dessa mesma obra, torna a conceituar o latim da Idade Média como ". . . a continuação do latim escolar e literário do baixo-impé10". Seguidor de Lфefstedt, NORBERG acentua o caráter "vivo" do latim da alta İade Média.

Christinne MOHRMANN (MOHRMANN, 1955) reconhece também ser o latim medieval, em uma certa medida, a continuação normal do latim literário tardio. Mas chama a atenção para o perigo de uma generalização, lembrando que as coisas n⿺辶 ocorreram do mesmo modo em todos os lugares. Assim, o que pode ser verdadeiro para a Itália e a Espanha, por exemplo, pode não sê-lo para a Gália ou a Irlandil,

Franz BLATT (apud MOHRMANN, 1955) considera toda a latinidade, denIro da qual está o latim medieval, como uma unidade. E vai mais adiante mesmo, hegando a ver uma separação mais nítida entre o latim profano e o cristão do qué entre o latim tardio e o medieval.

Para M. L. BIELER (apud MOHRMANN, 1955), a dificuldade em classificar 0 Latim medieval como fenômeno lingüístico reside no fato de não ter tido ele a funçı̆o de língua corrente de uma comunidade orgânica de falantes, constituindo-se nima lingua sem povo. Daí concluir afirmando ser ele uma língua de uma "Ideen"femeinsehaft".

Richard MEISTER (apud MOHRMANN, 1955), propondo uma definição lingdistica, defende firmemente, em um artigo intitulado Mittellatein als Traditionsiprase, a idéia de que o latim medieval foi uma língua falada e que, se não chega a lef uma língua viva no sentido estrito do termo, possui, contudo, traços de uma líniai viva, com evolução sintática, neologismos, empréstimos, etc. , devendo-se a evohị̂̆o nĭ́o a tendências literárias e cultas, mas aos impulsos espontâneos dos falan10i, decorrentes mesmo de seu caráter de língua falada. MEISTER é quem mais se aproxima da realidade lingüística, mas, mesmo assim, o problema não fica de todo reisolvido.

Longe de pretender ter esgotado a lista de autores que se voltaram para essa drea de estudos, o que se quer examinar, aqui, são as idéias de Christinne MOHR MANN, lucida e inteligentemente expostas

Lembra a autora que o latim da Idade Média se afasta, em muitos aspectos, dai regras formuladas pelos manuais em uso, infringindo muitos preceitos da doutriia r ramatical da época. Esse latim apresenta traços que o aproximam de uma língua viva, mas as modificações sofridas não se devem somente à oralidade. Uma grande parte da evolução advém muito mais da literatura, da língua escrita, do que de um ise oral, E, mais ainda, convém não exagerar esse caráter de língua "viva". O latim he liga, antes de tudo, à tradição antiga - profana e crista - da qual jamais se desprendeu inteiramente.
MOHRMANN coloca a questão de se saber se é possível encontrar uma definição lingüística que permita a apreciação dos textos latinos medievais enquanto documentos lingüísticos. Começa por lembrar ter sido sugerido ser o latim medieval uma língua literária. F. di CAPUA, por exemplo, fala do "latim literário medieval", visto tal latim como uma língua literária adaptada à sociedade medieval. Mas não se pode dizer que ele o tenha sido na acepção usual do termo, pois a esse latim adotado por tantos povos, durante tantos séculos, como língua de comunicação escrita e, por vezes, falada, faltava a terra nutriz da língua corrente e viva, condição mesma da existência de uma língua literária stricto sensu. Na verdade, o latim medieval, como fenômeno lingüístico, está muito próximo da língua literária. A Filologia Clássica e a Lingüística se valem da expressão "Kunstsprache" para caracterizar um tipo especial de língua literária. Aqui, entende-se pela expressão não as línguas fundadas sobre uma comunidade étnica, mas baseadas na tradição de uma coletividade ligada pela força unificadora de uma idéia. de uma tradição de caráter literário ou religioso, inspirada por fatos de ordem cultural em geral.

$\mathrm{O}$ agente da latinidade medieval foi a comunidade intelectual, que, suprimindo fronteiras de povos e nações, constituiu uma unidade: a republica clericorum (tomado o termo clericus no sentido amplo em que era usado na Idade Média: os clerici ou litterati eram os "letrados"). E essa força unificadora era sustentada não só pela afinidade religiosa como também pela firme convicção de ser essa coletividade a herdeira e a guardiã da tradição clássica.

Assim, o latim medieval foi uma língua viva sem ter sido a língua de uma comunidade étnica; foi o veículo de comunicação de uma elite fundada sobre uma tradiç̃o religiosa e cultural. Como língua de cultura, transmitida pela escola, ela é, em primeiro lugar, uma língua escrita e, só depois, língua falada.

Essa língua, fundada, de um lado, sobre a unidade da religião cristã e sobre a herança paleocristã e, de outro modo, sobre a herança da Antigüidade Clássica, reveste-se de um caráter dualista que remete a um outro problema: segundo que normas se hão de apreciar os textos latinos medievais?

Não é pequeno o número de autores que pretende sejam os padróes da Antigüidade Clíssica os adotados no julgamento das produções literárias da Idade Média. Mas é preciso lembrar que as obras da Idade Média não foram uma imitação pura da Antigüidade Clássica e que o humanismo medieval não foi, seguramente, um empréstimo servil e passivo. Tratou-se, antes de tudo, de uma conquista progressiva, representada pela transposição de certos elementos antigos no mundo medieval, in finitamente diferente do mundo antigo. O pretendido não era uma simples re constituiç̃o, mas uma utilização da herança clássica, cujo patrimônio era visto como uma força auxiliar através da qual se desejava enriquecer a civilização crista e medieval. O que se deve fazer não é estudar a Antigüidade Clássica através da Ida de Média, mas, antes, considerar a cultura medieval como um fenômeno autônomo.

$\mathrm{O}$ humanismo medieval foi, sem dúvida, uma criação original da Idade Média. Ele fica muito a dever a Santo Agostinho, que o entendia como um processo de adaptação e de utilização de elementos antigos dentro de um painel de civilização cristã.

Retornando ao problema do latim medieval, a pergunta que se coloca é se esse latim teria refletido a vida e o pensamento da Idade Média, ou ter-se-ia limitado a uma simples imitaçĩo dos modelos clássicos.

Organon, Porto Alegre, is (15); 81 4, 1986. 
$\mathrm{Na}$ verdade, o latim medieval refletiu claramente toda uma mudança operada lenta e gradualmente durante os séculos que compreendem a Idade Média, e que consegue, por assim dizer, completar-se somente no curso do século XII, quando se podem ver sinais evidentes de uma outra ordem de valores que realizam o ideal augustiniano.

$\mathrm{E}$ os dois fios condutores acabam por fundir-se, resultando em uma nova unidade, que é esse latim medieval: de um lado, o elemento antigo e profano, transmitido pela escola; de outro, o elemento cristão, haurido da própria vida e saturado de cristianismo.

Se a escola iniciava o homem medieval na latinidade profana, a liturgia o aproximava da latinidade cristã. E esse último contato é o responsável por uma liberdade presente no latim da Idade Média, muito mais desembaraçado das peias do normativismo rígido dos clássicos.

Muito tempo se passou até que, vencido esse dualismo, integrados esses elementos em uma nova unidade, o latim medieval viesse a ser um instrumento au tônomo que, fundindo e superando suas duas peças básicas, existisse por si mesmo.

Para julgar, então, os textos medievais, não se há de recorrer nem às normas do latim clássico, nem aos padrões do latim cristão, mas tomar como base o próprio latim medieval, onde se encontrarão elementos clássicos ao lạdo de outros especificamente cristãos, além de muitos neologismos medievais e de elementos devidos à influência das línguas nacionais, todos eles fundidos e integrados em um grande painel, formando uma nova unidade : o latim medieval.

\section{BIBLIOGRAFIA CONSULTADA}

1 BLAISE, Albert. Manuel di latin chrétien. Strasbourg, Le Latin Chrétien, 1955. $221 \mathrm{p}$.

2 BLATT, Franz.Précis de syntaxe latine. Paris, IAC, 1952.395p.

3 CURTIUS, Ernst Robert. Literatura Européia e Idade Média Latina. Rio de Janeiro, INL, $1957.667 \mathrm{p}$.

4 GRANDGENT, C.H. Introdución al latín vulgar. Madrid, Consejo Superior de Investigaciones Científicas, $1952.384 \mathrm{p}$.

5 LEHMANN, K. Vorlesungen und Abhandlungen. Munich Is. ed.I1911.189p.

6 MOHRMANN, Christinne. Études sur le latin des chrétiens. Roma, Edizioni di Storia e Lețteratura, 1958. 468p.

7 Latin vulgaire, latin des chrétiens, latin médiéval. Paris, Klincksieck, 1955.54p.

8 NORBERG, Dag. Introduction a l'étude de la versification latine médiévale. Stockholm, Almqvis \& Wiksell, 1958.218p.

9 -.Manuel pratique de latin médiéval. Paris, Picard, 1968.212p.

10 PALMER, L. R. The Latin Language. London, Faber and Faber, 1977. 372p.

11 STRECKER, Karl. Introduction a l'étude de latin médiéval. Genève, Librairie $\mathrm{E}$. Droz, $1948.77 \mathrm{p}$.

Endereço para correspondência: Ramiro Barcelos, 1820/902

90210 Porto Alegre, RS,

Brasil. 